Virginia Commonwealth University VCU Scholars Compass

Biology and Medicine Through Mathematics

Conference

May 18th, 6:30 PM - 7:00 PM

\title{
Applying fMRI complexity analyses to the single- subject: a case study for proposed neurodiagnostics
}

Anca R. Radulescu

State University of New York at New Paltz

Emily R. Hannon

University of Colorado Boulder, hannon.emily.r@gmail.com

Follow this and additional works at: http://scholarscompass.vcu.edu/bamm

Part of the Behavioral Neurobiology Commons, Computational Neuroscience Commons, Medicine and Health Sciences Commons, and the Non-linear Dynamics Commons

http://scholarscompass.vcu.edu/bamm/2017/thursday/27

This Event is brought to you for free and open access by the Dept. of Mathematics and Applied Mathematics at VCU Scholars Compass. It has been accepted for inclusion in Biology and Medicine Through Mathematics Conference by an authorized administrator of VCU Scholars Compass. For more information, please contact libcompass@vcu.edu. 
Methods for accurate diagnoses of neurological problems would greatly improve modern medicine. Nonlinear dynamic tools have been statistically validated at the group level to identify subtle differences in system wide regulation of brain meso-circuits. In many cases, this increases clinical sensitivity over conventional analyses alone. In order to extend these methods to neurodiagnostics, however, we explored the feasibility of extracting information at the single-subject level. To illustrate how this may be done, we focused on two pairs of healthy individuals with psychological differences in stress reactivity. The first pair consisted of one subject of average reactivity, the other of exceptional reactivity (working as an explosive ordinance disposal technician in support of U.S. Navy SEAL missions). The second pair was chosen from a larger group of subjects (with identical task design and imaging parameters), in which we had previously established a link between prefrontal-limbic reactivity and efficiency of stress responses. We applied both statistical and nonlinear dynamic tools: principal component decomposition, cross-correlation and complexity (power spectral scale invariance). These analyses were chosen to capture key characteristics of the prefrontal-limbic meso-circuit, such as activation, connectivity, and control systems regulation. We compared single subject results with statistical results obtained for the larger group. Our conclusions suggest that complexity analyses may identify important differences at the single-subject level, supporting investigation of these techniques for neuro-diagnostic applications. 